\title{
Erratum to: Complementary school garden, nutrition, water, sanitation and hygiene interventions to improve children's nutrition and health status in Burkina Faso and Nepal: a study protocol
}

Séverine Erismann 1,2, Akina Shrestha ${ }^{1,2,3}$, Serge Diagbouga ${ }^{4}$, Astrid Knoblauch ${ }^{1,2}$, Jana Gerold ${ }^{1,2}$, Ramona Herz ${ }^{1,2}$, Subodh Sharma ${ }^{3}$, Christian Schindler ${ }^{1,2}$, Peter Odermatt ${ }^{1,2}$, Axel Drescher ${ }^{5}$, Ray-yu Yang ${ }^{6}$, Jürg Utzinger ${ }^{1,2}$ and Guéladio Cissé 1,2* $^{*}$

\section{Erratum}

After publication of the original article [1], it came to the authors' attention that the Trial registration URL provided in the abstract was not correct. An internal link was supplied, so the original article has been updated to include the correct URL (http://www.isrctn.com/ISRCTN17968589) in the abstract.

\section{Author details}

'Swiss Tropical and Public Health Institute, P.O. Box, CH-4002, Basel, Switzerland. 'University of Basel, P.O. Box, CH-4003, Basel, Switzerland. ${ }^{3}$ Kathmandu University, P.O. Box 625045200 Dhulikhel, Nepal. ${ }^{4}$ Institut de Recherches en Sciences de la Santé, P.O. Box 7192, Ouagadougou 03, Burkina Faso. ${ }^{5}$ University of Freiburg, Friedrichstr. 39, D-79098 Freiburg im Breisgau, Germany. ${ }^{6}$ AVRDC - The World Vegetable Center, P.O. Box 4274151 Shanhua, Taiwan.

Published online: 05 July 2016

\section{Reference}

1. Erismann S, Shrestha A, Diagbouga S, Knoblauch A, Gerold J, Herz R, et al. Complementary school garden, nutrition, water, sanitation and hygiene interventions to improve children's nutrition and health status in Burkina Faso and Nepal: a study protocol. BMC Public Health. 2016;1:244. doi:10. 1186/s12889-016-2910-7.

* Correspondence: gueladio.cisse@unibas.ch

${ }^{1}$ Swiss Tropical and Public Health Institute, P.O. Box, CH-4002, Basel, Switzerland

2University of Basel, P.O. Box, CH-4003, Basel, Switzerland

Full list of author information is available at the end of the article

\footnotetext{
Submit your next manuscript to BioMed Central and we will help you at every step:

- We accept pre-submission inquiries

- Our selector tool helps you to find the most relevant journal

- We provide round the clock customer support

- Convenient online submission

- Thorough peer review

- Inclusion in PubMed and all major indexing services

- Maximum visibility for your research
}

Submit your manuscript at www.biomedcentral.com/submit 